Huru bör Sveriges of ficiella statistik reformeras?

Author(s): Thor Andersson

Source: Ekonomisk Tidskrift, Årg. 5 (1903), pp. 220-228

Published by: Wiley on behalf of The Scandinavian Journal of Economics

Stable URL: http://www.jstor.org/stable/3436824

Accessed: 23-06-2016 15:16 UTC

Your use of the JSTOR archive indicates your acceptance of the Terms \& Conditions of Use, available at

http://about.jstor.org/terms

JSTOR is a not-for-profit service that helps scholars, researchers, and students discover, use, and build upon a wide range of content in a trusted digital archive. We use information technology and tools to increase productivity and facilitate new forms of scholarship. For more information about JSTOR, please contact support@jstor.org.

The Scandinavian Journal of Economics, Wiley are collaborating with JSTOR to digitize, preserve and extend access to Ekonomisk Tidskrift 


\section{Huru bör Sveriges officiella statistik reformeras?}

\section{Af Thor Andersson.}

»För att regera stater väl måste man framför allt noggrannt känna dem», har det sagts för mera än hundra år sedan. Medel till denna oundgängliga kunskaps vinnande är statistiken redan. Den blifver det i allt högre grad, i samma mån den kan fylla de allt mera omfattande fordringar, det sig rastlöst utvecklande samhällslifvet ställer på den. Den ofantliga betydelsen för ett samhälle af att besitta en tillförlitlig och väl ordnad statistik torde icke från något håll jäfvas. Men en förutsättning, för att statistiken skall kunna lösa sin så kräfvande uppgift, är, att den själf äger förmåga till fortgående reformering och utveckling.

Den svenska statistiken, som en gång intagit en af utlandet uppmärksammad ställning, har för länge sedan måst afträda frăn sin rangplats, därmed svikande de fordringar en mellanfolklig vetenskap och en inhemsk förvaltning ställa på den. Att den svenska statistiken - med undantag för befolkningsstatistiken - allt mindre tillfredsställer de sig oupphörligt ökande fordringar, som modern vetenskap och förvaltning kräfva, förorsakas hufvudsakligen af den föråldrade organisation, hvarunder den svenska statistiken, trots de kraftiga reformansatserna för femtio år sedan, alltjämt arbetar. Därmed sammanhänger det missförhållandet, att med den fortgående utvidgningen af Sveriges officiella statistik, den statistiska fackinsikten fått och får allt mindre göra sig gällande. Stora områden af den officiella statistiken bearbetas af dussinstatistiker, hvilka - för att tala med samtidens törhända förnämste statistiker, professorn vid universitetet i Berlin L. v. Bortkiewicz - utgå från ett gifvet statistiskt material, bearbeta detta med beräkningar efter en bestämd schablon, uppställa kronologiska och andra talräckor, eventuellt efter bepröfvade mönster 
uppgöra diagram och kartogram och öfverflytta hufvudresultaten från tabellerna $i$ ord. Att det finnes högre, öfver fastställandet af rena sakförhållanden sträfvande kunskapsmål, är för dessa s. k. statistiker främmande. Denna ovetenskapliga behandling af ett vetenskapligt ämne, som är den vanliga byråkratiska, blifver, om möjligt, ännu sämre, då såsom i Sverige stora delar af den officiella statistiken utlämnats åt »tjänstemän, hvilka under ett eller annat år utföra statistiskt arbete, måhända blott som bisyssla», och på platser, »som betraktas såsom genomgångsplatser inom ett verk, hvars hufvudändamål är af helt annat slag».

En genomgående reformering af Sveriges officiella statistik är således af behofvet särdeles påkallad. Förutsättningarna för det lyckliga genomförandet af en sådan reform äro också goda. Ett medborgerligt statistiskt pliktmedvetande gör sig i Sverige allt mera gällande. De uttryck, det bland annat tagit i svenska handels- och näringsidkares så ofta och allt bestämdare uttalade redobogenhet att $\mathrm{i}$ deras mån bidraga till åstadkommande af den handels- och näringsstatistik, som numera är ett oundgängligt medel till deras kamp för tillvaron $\mathrm{i}$ den allt större täflan på den ekonomiska marknaden, vittna mera än nog därom. Sverige har för närvarande dessutom förmånen att äga framstående statistiker - professor Fahlbeck, förste aktuarien Sundbärg och aktuarien Flodström - hvilka väl inse reformens nödvändighet och $\mathrm{i}$ ord och skrift i flera hänseenden gifvit beaktansvärda uppslag för den riktning, $i$ hvilken reformen på skilda områden bör gå. Därtill kommer, att de afsevärda belopp, som för statistiskt ändamål nu utgå, ovillkorligen skola kunna utnyttjas på ett verksammare sätt, om en sådan omorganisation af Sveriges officiella statistik företages, där äfven utlandets nyare och rika erfarenhet inom detta område får göra sig gällande.

Det är en i innevarande riksdags första kammare af lektor Nyström väckt motion, som sent omsider uppfört frågan om Sveriges officiella statistiks reformering på den politiska dagordningen. Riksdagen har, efter likalydande hemställan från vederbörande tillfälliga utskott i bägge kamrarna, beslutat att i skrifvelse till Kongl. Maj:t anhålla om verkställandet af utredning, huru inom rikets officiella statistik största möjliga enhet och planmässighet $\mathrm{i}$ arbetet äfvensom ökad skyndsamhet vid publikationen må kunna åstadkommas och att därvid särskildt måtte tillses, huruvida ej åt statistiska tabellkommissionen kunde gifvas en mera fackmässig sammansättning, samt om framläggande för riksdagen af denna utredning jämte de förslag, hvartill densamma må föranleda. 
Granskas motiveringarna till vederbörande utskotts hemställanden, är det icke svårt att skönja, det bägge utskotten varit fullt på det klara med behöfligheten af den officiella statistikens reformering. I hvilken riktning denna helst bör gå, därom hafva meningarna egentligen icke heller varit delade. „Ett sätt, det radikalaste», heter det i första kammareutskottets utlåtande, svore att sammanföra alla utom af motionären uppräknade grenar af den officiella statistiken - post-, järnvägs- och telegrafstatistik - till ett och samma ämbetsverk, den statistiska centralbyrån, på så sätt återupptagande tankarne från I 854. Det är tydligen denna utväg, som mest tilltalar motionären och som otvifvelaktigt ock vore den rationellastes. I andra kammarens utskott var man så intagen för denna reformplan, att i utskottets ursprungliga skrifvelseförslag hemställes om utredning, endast huru inom rikets officiella statistik mera enhet och planmässighet $\mathrm{i}$ arbetet äfvensom ökad skyndsamhet vid publikationen må kunna åstadkommas.

Men så kommo hänsynen till de svenska ämbetsverken, som förstört vår en gång så lysande statistik, hvilken kommer att hållas kvar i sitt nuvarande förfall, så länge som de svenska ämbetsverkens intressen först måste tillgodoses, äfven om hela Sveriges förvaltning, såsom här är fallet, tager allt större skada med hvar dag som går. Ämbetsverkens åsikter i reformfrågan hafva tagit sig uttryck i ett yttrande, som afgifvits rörande lektor Nyströms motion till andra kammarens utskott af kommerskollegium och statistiska centralbyrån och som är undertecknadt af nämnda ämbetsverks chefer samt förste aktuarierna Söderberg och Gullberg. "Själfva det mål», säges det i yttrandet, »som de i motionen angifna åtgärder åsyfta, eller att bereda den största möjliga enhet åt det statistiska arbetet, kan icke $\mathrm{i}$ och för sig anses såsom något eftersträfvansvärdt, utan endast för så vidt andra berättigade intressen därigenom ej åsidosättas». Allt är bra som det är, låter grundtonen i yttrandet. Önskas förbättringar, så behöfves mera pengar, förklara ämbetsverken, hvilka väl anse, att staten redan nu får så stor valuta, som kan åstadkommas, för de många till statistiska ändamål utgående anslagen.

Hänsyn till vissa förhållanden gjorde, att andra kammarens utskott öfvergaf sin ursprungliga ståndpunkt och gick med på första kammarutskottets hemställan. Det var nämligen icke alldeles uteslutet, att, om andra kammarutskottet framhärdat $\mathrm{i}$ sin ursprungliga mening, motionen denna gång icke kommit att föranleda till någon riksdagens åtgärd. Därmed hade den så behöfliga reformen af den officiella statistiken uppskju- 
tits. Men har andra kammarutskottet funnit sig i denna taktiska eftergift, să har det i själfva verkligheten icke gifvit mycket efter af sin ursprungliga åskådning. Motiveringen lägger äfven $i$ dess slutliga form tydligt $i$ dagen utskottets obenägenhet för hvarje annan reform af den officiella statistiken än den, som det först tänkt sig.

Äfven första kammarutskottets motivering är icke någon lofsång öfver det nuvarande systemets möjlighet till reformering. Utskottet fortsätter det här ofvan anförda uttalandet om den otvifvelaktigt rationellaste reformen på följande sätt: »Men utom denna, för närvarande $\mathrm{i}$ mångas ögon kanske väl omstörtande, reform gifves det en annan, jämförelsevis obetydlig men därför ej overksam, den nämligen som, med bibehållande af den nuvarande yttre fördelningen af landets statistik, blott söker åstadkomma en större samverkan mellan dess olika grenar samt en mera fackmässig ledning af dessa. Det är denna utväg, som motionären i andra hand anbefaller, då han förordar en omorganisation, af den statistiska tabellkommissionen $\mathrm{i}$ syfte att gifva den en fătaligare men mera fackmässig sammansättning hvad de ordinarie ledamöterna beträffar, och i sammanhang därmed vill utvidga dess verksamhetsområde genom att åt den anförtro utgifvandet af en statistisk årsbok. Genom detta förslag afhjälpes visserligen icke direkt den ofvan antydda stora olägenheten, att icke-fackmän inom så många grenar fortfarande komma att handhafva den officiella statistiken; men denna olägenhet kan dock väsentligen minskas, om den statistiska tabellkommissionen mera än hittills sättes i stånd att följa hvarje gren af statistik samt utöfva den kritiska granskning af metoder och bearbetning, som de underordnade organen icke själfva förmå utföra.»

Icke-fackmän skola alltså fortfara att handhafva många grenar af den officiella statistiken. Olägenheterna däraf skola minskas genom kritisk granskning af tabellkommissionen, säges det vidare. Vid en målmedveten reform kan det icke vara mål att minska de olägenheter, som redan förefinnas, utan att fullständigt aflägsna dem. Det kan aldrig ske annat än genom att endast fackmän utföra allt statistiskt arbete. Skola icke-fackmän alltjämt få handhafva olika grenar af rikets statistik, måste deras arbete ställas under oafbrutet öfvervakande, såvida det icke skall blifva alltför otillförlitligt. Fullödigt blifver det aldrig. Ett sådant oafbrutet öfvervakande kan en tabellkommission aldrig utföra, vare sig med den sammansättning, den nu har, eller med en sammansättning liknande den, som föresväfvat motionären eller första kammarutskottet. En reform i denna rikt- 
ning blifver endast en skenreform, som icke bringar Sveriges officiella statistik till den höjdpunkt, dit den bör och kan komma.

Sveriges officiella statistik är i närvarande stund fördelad på I 5 olika ämbetsverk. Man har således kommit så fjärran som möjligt från det önskemål, som Rikets Ständer angåfvo redan vid 1853-54 års riksdag, då de förklarade sig anse att såtgärder böra vidtagas för att, så șnart omständigheterna det medgifva, erhålla en sådan i möjligaste mån fullständig fortgående statistik, hvilket ändamål ctvifvelaktigt säkrast vinnes genom bildandet af ett ämbetsverk, som finge sig uppdraget att uppgöra planen till de statistiska arbetena i deras särskilda grenar, äfvensom att sammanföra, bearbeta och offentliggöra de inkomna uppgifterna och sålunda bereda erforderliga upplysningar om landets tillstånd, utveckling och förkofran. Med ett sådant ämbetsverk kunde då de arbeten, som för statistiska ändamål utföras inom särskilda ämbetsverk, sättas i förening, och tabellkommissionen, den enda inrättning, som varit ägnad uteslutande åt statistik, ehuru endast åt en enda gren däraf, upphöra.»

Under de femtio år, som förflutit, sedan riksdagen gjorde detta hufvuduttalande rörande den officiella statistiken, har i Sverige ingenting inträffat, som icke håller det anförda uttalandet upprätt. Tabellkommissionen upphörde väl till namnet, men kom i verkligheten att, trots riksdagens anhăllan, lefva upp igen i statistiska beredningen, som I 886 förändrades till statistiska tabellkommissionen. För deras verksamhet redogöres i ämbetsverkens anförda yttrande. Detta bestyrker motionärens uppgift, att kommissionen i senare tid sällan sammanträdt, sedan 1874 »endast I à 2 gånger $\mathrm{i}$ medeltal per år och stundom med betydande tidsafbrott». Det tyckes gifva vid handen, att den nuvarande tabellkommissionens hela verksamhet torde kunna upphöra utan någon egentlig skada för de intressen, den skulle tillgodose, och hvilka den blifvit och blifver allt mera urståndsatt att tillvarataga.

Skall en reform på den svenska statistikens område $\mathrm{i}$ våra dagar hafva afsedd verkan, bör den omfatta hufvud och lemmar. Det tillvägagångssätt, som så ofta gör sig gällande på olika områden inom lagstiftning och förvaltning, eller en stegvis småningom försiggående förändring, lämpar sig icke $\mathrm{i}$ detta fall. För statistiken behöfliga reformer måste genomföras målmedvetet och fullständigt, dock så, att i högsta möjliga mån sammanhanget med det förutvarande bevaras, hvarigenom tillbakagående jämförelser möjliggöras. Dylika för statistiken så godt som oundgängliga jämförelser försvåras och omöjliggöras understundom genom 
många och för tätt på hvarandra följande mindre förändringar i statistikens organisation eller bearbetningssätt.

Erfarenheten från utlandet talar äfven för att den numera enda riktiga vägen för en reform af Sveriges officiella statistik är utlösandet af de statistiska arbetena ur så många som möjligt af de femton olika ämbetsverk, i hvilka de för närvarande bearbetas och utgifvas, och deras sammanförande i statistiska centralbyrån, Sveriges egentliga åt statistik ägnade ämbetsverk. Sträfvan efter utlösning och sammanföring under enhetlig ledning gör sig allt kraftigare gällande i många af Europas stater, såsom Tyskland, Italien, Ungarn m. fl. Erfarenheten frăn Frankrike och dess I 885 i handelsministeriet upprättade Conseil supérieur de statistique visar äfven, att ett rådgifvande organ för hela den statistiska förvaltningen icke förmått häfva de stora och principiella bristerna i den franska förvaltningsstatistikens organisation. Det kan endast ske genom en strängt genomförd utlösning och sammanslagning af de statistiska byråerna i de skilda ämbetsverken.

\All officiell statistik bör stå under gemensam ledning och så vidt möjligt koncentreras» är den af motionären uttalade grundsats, hvilken bör vara ledmotivet för en blifvande reform. Med utlösandet af post-, telegraf- och järnvägsstatistiken kan anstå tillsvidare. Utlösas med angifna undantag de af de olika ämbetsverken utgifna statistiska arbetena och förläggas till statistiska centralbyrån, måste denna utvidgas och fullständigt omorganiseras. Detta behöfver dock ingalunda medföra några väsentligare utgifter för statsverket, då det hufvudsakligen blott handlar om en omflyttning för att erhålla bättre valuta af redan utgående kostnader för den officiella statistiken.

I spetsen för statistiska centralbyrån kan ställas statistiska centralbyråns styrelse, bestående af statistiska centralbyråns chef och ett lämpligt antal afdelnings- eller byråchefer. I vissa fall kan styrelsen förstärkas med fackmän från universiteten eller där eljest sådana finnas att tillgå samt $\mathrm{i}$ fråga om närings- och socialstatistik med representanter för de intresserade.

Med fäst afseende vid de uppgifter, hvilka närmast skulle komma afdelnings- eller byråcheferna till del, och med tanke på den historiska ordning och betydelse, de olika näringarna hafva i den svenska samhällsutvecklingen, torde afdelningschefernas antal till en början kunna begränsas till sex eller sju. Afdelningscheferna skola stå i spetsen för hvar sin byrå.

Följande skema visar huru, med ofvan gjorda undantag, de olika 
ämnen, som för närvarande behandlas inom serien Bidrag till Sveriges officiella statistik, möjligen till en början skulle kunna fördelas på sex byråer:

Byrån för utgifver af bidragen littera

I. Befolknings-, hälso- och sjuk- (A) Befolkningsstatistik; domsstatistik ..... (K) Hälso- och sjukvården.

2. Jordbruksstatistik ..... $\begin{aligned} & \text { N) Jordbruk och boskapsskötsel I \& II; } \\ & \text { O) Landtmäteriet; } \\ & \text { Q) Statens domäner; } \\ & \text { S) Allmänna arbeten. }\end{aligned}$

3. Industri- och socialstatistik $\cdots\left\{\begin{array}{l}\text { C) Bergshandtering; } \\ \text { D) Fabriker och manufakturer; } \\ \text { X) Afönings- och pensionstatik }\end{array}\right.$

X) Aflönings- och pensionsstatistik.

4. Handels- och sjöfartsstatistik . $\begin{aligned} & \text { E) Inrikes sjöfart och handel; } \\ & \text { F) Utrikes handel och sjöfart; }\end{aligned}$

T) Lots- och fyrinrättningen;

De månatliga uppgifterna om rikets in- o. utförsel.

(H) Kungl. Maj:ts Befallningshafvandes Femårsberättelser;

U) Kommunernas fattigvård och finanser;

5. Finansstatistik ....... $\begin{aligned} & \text { V) Brännvinstillverkning och försäljning samt hvit- } \\ & \text { betssockertillverkningen; }\end{aligned}$

Y) Sparbanksstatistik Afd. I \& II;

Bankrapporterna;

Generalsammandraget af bevillningen;

Kapitalkonto till rikshufvudboken.

6. Rätts- och undervisningsstatistik $\left\{\begin{array}{l}\text { B) Rättsväsendet; } \\ \text { G) Fångvården; } \\ \text { P) Undervisningsväsendet; } \\ \text { R) Valstatistik. }\end{array}\right.$

Till några af de föreslagna byråerna torde inom kort nya statistiska arbeten anförtros. Rättstatistiken har i Sverige med det för icke länge sedan införda straffregistret fătt ett statistiskt material af stort värde, hvars bearbetande icke får anstå. Till den femte byrån hör en blifvande inkomststatistik, för hvilken själfdeklarationen snart gifver det fasta grundlaget. Maltskattens införande skall skapa en länge saknad grundval för statistiken öfver maltdryckernas produktion och konsumtion. Försäkringsstatistiken hör äfven där hemma.

Den tredje byrån är sannolikt den hvars arbetsuppgifter under den närmaste framtiden hafva att motse den största ökningen. Fråga kan vara om det icke är lämpligt att genast från början inrätta en särskild byrå för industristatistik och en för socialstatistik. Den sistnämnda skulle då åligga först och främst de socialstatistiska uppgifter, om möjligt i mycket utvidgad omfattning, som nu bearbetas i kommers- 
kollegiets arbetsstatistiska afdelning. Vidare bör under ompröfning tagas, huruvida icke yrkesinspektörernas berättelser och riksförsäkringsanstaltens blifvande olycksfallsstatistik här böra få den sakkunniga behandling, hvaraf de äro i så stort behof.]

Den svenska riksförsäkringsanstalten borde med dess nuvarande verksamhetsområde hafva en personal, hvaraf en stor del skulle vara fackbildade olycksfallsstatistiker. I dess ställe finnes där för närvarande icke någon, som kan fylla de rimligaste anspråk på vetenskaplig bildning $\mathrm{i}$ statistik i allmänhet och ännu mindre i olycksfallsstatistik - det svåraste området af all statistik. Hela Sverige har numera största intresse i den snara tillkomsten af en olycksfallsstatistik, som bjuder något mera än de magra notiser, som segla under olycksfallsstatistikens flagg $i$ in- och utland. Det är den första trängande uppgiften för en blifvande kommitté för rikets statistik att skapa det skema, hvarefter Sveriges olycksfallsstatistik skall utarbetas.

En byrå för socialstatistik skall äfven kunna tillvarataga det icke sällan så värdefulla statistiska material, som det enskilda föreningsväsendet i landet åstadkommer, hvilket nu alltför ofta förblifver obearbetadt eller bearbetas på ett otillfredsställande sätt. Samma byrå kunde också blifva en bindande länk mellan Sveriges officiella statistik och den kommunala statistik, som tidsförhållandena hos oss för länge sedan gjort behöflig och hvilkens så godt som fullständiga obefintlighet hittills kan förklaras ur den bristande insikten om dess nytta.

Allmänhetens och i synnerhet näringsidkarnes kraf på största skyndsamhet vid offentliggörandet af för dem viktiga meddelanden bör tillgodoses, törhända helst genom en veckopublikation, som fyller samtidens fordringar. Då den tyska rikshufvudstaden redan utgifver veckomeddelanden, torde det icke vara för tidigt att ifrågasätta en med så korta mellanrum återkommande statistisk publikation för ett helt rike. Skall en statistisk årsbok utgifvas, bör den efter mönster från de australiska staterna offentliggöras $\mathrm{i}$ delar, allt efter som det statistiska materialet blifver tillgängligt.

Ordnas den officiella statistiken i här angifven riktning, torde säkrast verklig enhet och planmässighet $i$ arbetet äfvensom ökad skyndsamhet vid publikationen kunna åstadkommas. Statistiken erhåller då öfver hela linjen den fackmässiga bearbetning, hvaraf den för hvarje dag som går är $\mathrm{i}$ allt större behof. Samarbetet mellan fackmän på olika statistiska områden bör verka befruktande på hela arbetet och reform- 
uppslagen böra icke längre blifva främmande för den officiella statistikens egentliga handhafvare.

De här berörda frågorna och andra därmed i samband stående spörsmål angående en fullt tidsenlig anordning af Sveriges officiella statistik lära icke på ett tillfredsställande sätt kunna lösas utan efter en föregående utredning af landets yppersta fackmän. De fackkunniga må för vissa uppgifter - sådana, som röra exempelvis närings- och socialstatistik - tillkalla representanter för de intresserade, hvilka äfven sedermera utan svårighet torde få rikligt tillfälle att yttra sig öfver ett blifvande kommittébetänkande. Uppgiften att utarbeta förslag till en omorganisation af rikets statistik är så godt som uteslutande en vetenskaplig uppgift. Inga andra än fackbildade statistiker duga heller till lösandet af uppgiften.

Statistiken är $\mathrm{i}$ văra dagar icke endast en metod, utan äfven en vetenskap med ett alldeles bestämdt innehåll, som icke låter inordna sig under en annan vetenskap. Försöken att inympa befolkningsstatistiken $\mathrm{i}$ nationalekonomien hafva icke lyckats. Sociologien håller på att blifva till och gör af statistiken endast sällan bruk.

Denna statistikens plats i det moderna vetenskapliga lifvet berättigar redan dess själfständiga representerande vid svensk högskola. En utlösning af statistiken från nuvarande ämneskoppling och dess förseende med egen lärostol blifver så mycket mera af nöden, om en genomgående reform af Sveriges officiella statistik företages. Statistiken måste då vinna själfständighet bland disciplinerna, om den skall kunna tillgodose statens och samhällets växande behof af statistisk fackkunskap. Statistikens ställning vid högskolorna bör uppmärksammas af en blifvande kommitté.

Kommittéen får icke heller underlåta att undersöka, hvilka af statistiska centralbyråns äldre handlingar böra offentliggöras, för att Sverige skall fylla några af sina många och stora skyldigheter mot den mellanfolkliga statistiska vetenskapen, i hvilkens namn jag här djärfves taga till orda. Den mellanfolkliga statistiska vetenskapens yppersta idkare följa med lifligaste intresse den svenska officiella statistikens öden och framställa nu genom en deras lärjunge den anhållan: "Lös ut statistiken ur ämbetsverken och för samman det mesta möjliga i en reformerad statistisk centralbyrå».

Därmed tjänas bäst rikets egna intressen, på samma gång Sverige åter blifver $i$ stånd att fylla sina skyldigheter mot den mellanfolkliga vetenskapen. 